DOI: 10.5604/01.3001.0012.0717

\title{
OCENA RUCHU PALIWA W PROCESIE SPALANIA NA PODSTAWIE OBRAZU CYFROWEGO
}

\author{
Lukasz Pater \\ Politechnika Wrocławska, Wydział Elektroniki, Katedra Automatyki Mechatroniki i Systemów Sterowania, Zakład Systemów Wizyjnych i Teorii Sterowania
}

Streszczenie. Artykut dotyczy sposobu wskazania rodzaju ruchu przy pomocy przetwarzania $i$ analizy obrazu cyfrowego na przykładzie sekwencji przemieszczania sie pylu weglowego. Prezentowane podejście ma poszerzyć perspektywe zastosowania systemów wizyjnych w kontroli procesów spalania, podnosząc tym samym ich efektywność. Wyniki pokazaly wlaściwe odzwierciedlenie rzeczywistego ruchu paliwa na dyskretnej powierzchni pól wektorowych przy zastosowaniu metody przeplywu optycznego. Dołaczenie metody numerycznej, do analizy pól wektorowych, pozwoliło wyznaczyć sześć rodzajów ruchu. Obserwacje, obejmujące fragmentu badanego zjawiska, wyczerpują wszystkie przypadki oceny przemieszczenia czastek paliwa.

Słowa kluczowe: analiza ruchu na obrazie, przemysł węglowy, metoda różnic skończonych, pola wektorowe

\section{ASSESSMENT OF FUEL MOVEMENT IN COMBUSTION PROCESS BASED ON THE DIGITAL IMAGE}

\begin{abstract}
The article refers to the method of indicating the type of movement by means the digital image processing and analysis on the example of a coal dust movement sequence. Presented approach is broaden the perspective of use the vision systems in the combustion processes control, thus increasing their effectiveness. The results showed a correct reflection of the real fuel movement in the discrete surface of the vector fields using the optical flow method. Including a numerical method for vector field analysis allowed to indicate six types of movement. Research, covering a fragment of the studied phenomenon, exhaust all cases of assessing the fuel particles displacement.
\end{abstract}

Keywords: image motion analysis, coal industry, finite difference methods, vector fields

\section{Wstęp}

Jednym ze stosowany paliw w produkcji jest węgiel. Dostarcza on ponad $30 \%$ zapotrzebowania na energię oraz $40 \%$ zapotrzebowania na elektryczność w skali świata. Bierze udział w produkcji $70 \%$ stali w skali światowego rynku $[6,12]$.

W dobie rosnącego zapotrzebowania i stosowania energii odnawialnych [11], węgiel nadal ma największe znaczenie w produkcji, a jego zużycie stale rośnie. Paliwem może być zarówno sam sproszkowany węgiel [3], nazywany pyłem węglowy, jak i mieszanki pyłu węglowego $\mathrm{z}$ innymi produktami spalania [1,9]. Do takich mieszanek należą biopaliwa, które pozwalają na zmniejszanie kosztów produkcji oraz zmniejszenie emisji substancji szkodliwych. Stale rozwijane proporcje i rodzaje mieszanek, bez istotnych zmian układów spalania wymagają stałej kontroli.

Automatyzacja pomiaru procesu spalania za pomoca obrazu rejestrowanego przez kamery, od ultrafioletu po podczerwien, jest dobrze znana i stale rozwijana. Jak pisze Hobson i in. [8] zmiany ekonomiczne wpływają na rodzaj węgla w elektrowniach. Przeprowadzają oni badania kontroli jakości paliwa przez analizę obrazu cyfrowego, w zakresie światła widzialnego, wskazując różnice tekstury węgla względem innym skał. Carter i in. [5] przedstawiają wyniki pomiaru cząstek paliw, dostarczanych na bieżąco do kotła spalania, za pomocą kamery cyfrowej umieszczonej w rurociągu dolotowym. Znanych jest również wiele badań analizy samego płomienia podczas spalania paliwa [7].

W niniejszym artykule przeprowadzono badanie oceny rodzaju ruchu naturalnego paliwa stałego, na podstawie zarejestrowanej sekwencji obrazu cyfrowego w zakresie światła widzialnego. Motywacją badania jest wpływ podania i ruchu paliwa na przebieg spalania.

\section{Metodyka}

Badanym stałym paliwem opałowym był pył węglowy. Ruch pyłu węglowego wymuszono przez zasilenie palnika o szerokości ok. $80 \mathrm{~mm}$ (element 4, rys. 1a). Do badań, palnik umieszczono nad rurą opadową, o szerokości $130 \mathrm{~mm}$ (element 5 , rys. 1b). Palnik wyposażony jest $\mathrm{w}$ trzy kanały wlotowe (elementy $1-3$, rys. 1a). Jednym z kanałów, centralnym (element 1, rys. 1a), dostarczane jest paliwo. Pozostałymi dwoma kanałami (element 2 i 3, rys. 1a) dostarczana jest mieszanka gazowa, tlenu i dwutlenku węgla. Gaz pełni funkcję transportową, wpływa na ruch paliwa oraz bierze udział w procesie spalania paliwa. Ilość dostarczanego paliwa oraz gazu, wykorzystanie kanałów dolotowych gazu czy też proporcja mieszanki gazowej jest w pełni kontrolowana. $\mathrm{Na}$ zarejestrowanej sekwencji (rys. 1c), pył węglowy porusza się z góry na dół. Prędkość badanego paliwa mieści się w zakresie od 3 do $8 \mathrm{~m} / \mathrm{s}$. Pozostawiając przestrzeń na rejestrację obrazu oraz zbieranie wylatującego paliwa (rys. 1), pył węglowy nie jest spalany.

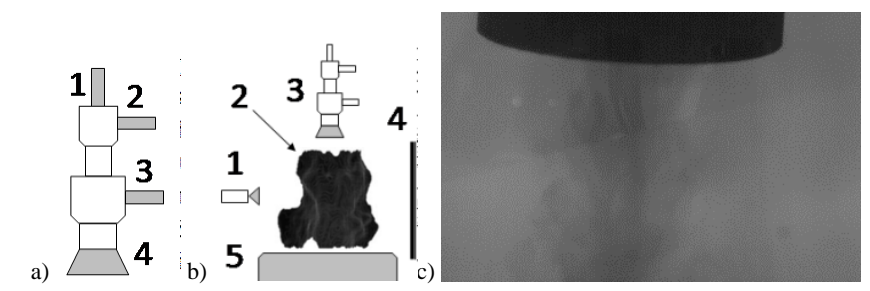

Rys. 1. Pogladowe rysunki a) palnika doprowadzajacego paliwo: 1 -doprowadzenie paliwa, 2, 3- gazu transportowego, 4-wylot palnika, b) sposobu rejestracji przeprowadzanego badanego zjawiska: 1 -kamera rejestrujaca, 2 - rejestrowany pyt weglowy, 3 - palnik doprowadzajacy paliwo, 4 - tło zwiększajace kontrast ruchu paliwa, 5 - rura opadowa zbierajaca paliwo oraz c) jedna z zarejestrowanych ramek sekwencji o rozdzielczości $752 \times 480 \mathrm{px}$.

Analiza ruchu paliwa w sekwencji obrazu została podzielona na cztery kroki. Pierwszym krokiem jest odfiltrowanie zakłóceń urządzenia rejestrującego oraz sposobu rejestracji zjawiska. Drugim krokiem jest wyznaczenie pola wektorowego, opisującego w przybliżeniu ruch rzeczywisty. Trzecim punktem jest obliczenie wartości pochodnych cząstkowych z dyskretnej przestrzeni pól wektorowych. Czwartym, ostatnim krokiem są obliczenia na pochodnych cząstkowych w celu prezentacji dywergencji i rotacji ruchu. Wynik obliczeń, dywergencji oraz rotacji, jest opisem rodzaju przemieszczenia paliwa.

Do odfiltrowania ramek sekwencji, zaproponowano usunięcie tła (1) oraz wyrównanie histogramu. Usunięcie tła jest różnicą ramki wzorcowej i ramki aktualnie przetwarzanej:

$$
I_{\text {PRZETWORZONY }}=I_{B A D A N Y}-I_{W Z O R C O W Y}
$$

gdzie: $I_{P R Z E T W O R Z O N Y}$ - ramka wynikowa po przetworzeniu, $I_{B A D A N Y}$ - aktualnie analizowana ramka, $I_{W Z O R C O W Y}$ - ramka wzorcowa, na której nie został zarejestrowany ruch paliwa. Na obrazie różnicy, obrazie przetworzonym pozostaje ruch pyłu węglowego. $\mathrm{Z}$ powodu małego kontrastu badanego zjawiska, tylko połowa zakresu kwantyzacji, dodatkową filtracją ramki jest wyrównanie histogramu. Dla sekwencji odfiltrowanych ramek wyznaczana jest sekwencja pól wektorowych.

Z kolejno występujących po sobie, dwóch ramkach sekwencji, wyznaczono pole wektorowe. Wybrano metodą przepływu 
optycznego (ang. optical flow) Lucas-Kanade [4]. Jak pokazują wyniki pozostałych metod przepływu optycznego [2], metoda Lucas-Kanade wyznacza dość dobrze pola wektorowe dla obrazów rzeczywistych. Jest to lokalna metoda gradientowa. Polega ona na wyznaczeniu, z punktów sąsiednich, wektora ruchu. Dla większości punktów ramki, poza brzegowymi, wyznaczany jest wektor metodą najmniejszych kwadratów. Metoda liczy wektor w lokalnej przestrzeni, tzw. okna. Na podstawie punktów sąsiednich, znajdujących się w oknie, zakładamy, że przesunięcie nastąpiło w tym samym kierunku dla wszystkich punktów okna. Mniejsze okno wymaga krótszego czasu obliczeń, jednak wyznaczony wektor może znacznie odbiegać kierunkiem i długością od wektorów sąsiednich. Przyjęta wielkość okna, dla badanego zjawiska, to $40 \times 40$ pikseli. Wynikiem obliczeń jest sekwencja pól wektorowych.

Do przybliżenia wartości pochodnych składowych wektorów, w przestrzeni dyskretnej, zastosowano metodę różnic skończonych [10] (ang. finite difference method). Metoda numeryczna oblicza pochodne cząstkowe przez przybliżenia algebraiczne oparte o punkty sąsiednie. Punkty sąsiednie występują zarówna na jednej ramce, jak i na sąsiednich ramkach sekwencji, w przypadku liczenia pochodnej po czasie $t$ (rys. 2).

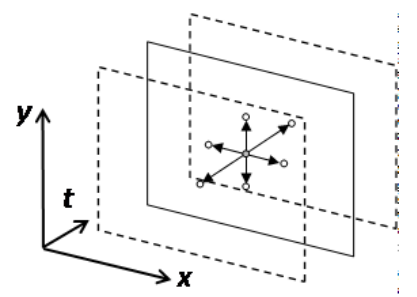

Rys. 2. Wizualizacja pobrania wartości sasiednich, na osi $x$, y oraz czasu dla metody różnic skończonych z trzech kolejnych ramek sekwencji obrazu

Dla dalszych obliczeń, wyprowadzone zostały wzory $(2-4)$ składowych wektora dla każdego przypadku przesunięcia względem dyskretnej przestrzeni:

$$
\begin{aligned}
& \frac{\partial P}{\partial x}=\frac{P(x+1, y, t)-P(x-1, y, t)}{2} \\
& \frac{\partial Q}{\partial x}=\frac{Q(x+1, y, t)-Q(x-1, y, t)}{2} \\
& \frac{\partial P}{\partial y}=\frac{P(x, y+1, t)-P(x, y-1, t)}{2} \\
& \frac{\partial Q}{\partial y}=\frac{P(x, y+1, t)-P(x, y-1, t)}{2} \\
& \frac{\partial P}{\partial t}=\frac{P(x, y, t+1)-P(x, y, t-1)}{2} \\
& \frac{\partial Q}{\partial t}=\frac{Q(x, y, t+1)-Q(x, y, t-1)}{2}
\end{aligned}
$$

gdzie: $P$ i $Q-$ składowe wektora przemieszczenia, $x$ - położenie punktu względem osi $\mathrm{x}, y$ - położenie punktu względem osi $\mathrm{y}$, $t$ - numer ramki z sekwencji. W dalszych krokach, powyższe obliczenia można przekształcić do maski, i obliczeń konwolucji obrazu. Wynikiem jest sekwencja pochodnych cząstkowych.

Przeprowadzone badania obejmują opis przemieszczeń paliwa w dwóch rodzajach ruchu. Pierwszym rodzajem ruchu jest dywergencją, na którą składają się trzy typu ruchu (rys. 3). Drugim rodzajem ruchu jest rotacja, na którą składają się trzy typu ruchu, z których dwa są kluczowe (rys. 4).
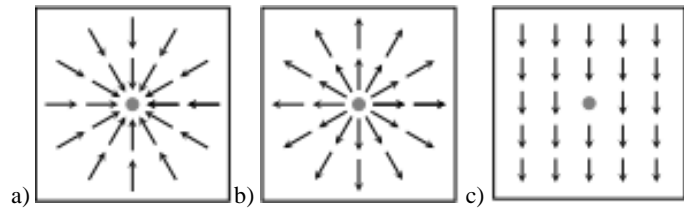

Rys. 3. Rodzaje badanych typów dywergencji: a) naptyw, b) odplyw, c) przeptyw
Pierwszym opisem przemieszczenia jest dywergencja, obliczana wzorem (5).

$$
\operatorname{div} F=\nabla \circ F=\frac{\partial P}{\partial x}+\frac{\partial Q}{\partial y}
$$

gdzie: $F$ - wektor przemieszczenia punktu, $P, Q$ - składowe wektora przemieszczenia. Za jej pomocą badamy czy sąsiednie obiekty napływają do punktu źródłowego (źródło ujemne) (rys. 3a), odpływają od niego (źródło dodatnie) (rys. 3b), czy też poruszają się stale bez zauważalnego napływu lub odpływu (bezźródłowe) (rys. 3c). Odpowiednio dywergencja $w$ tym punkcie przyjmuje wartości mniejsze do zera, większe od zera oraz równe zeru.

Drugim opisem przemieszczenia jest funkcja wektorowa, rotacja, obliczana wzorem $(6)$ :

$$
r o t F=\nabla \times F=-i\left(\frac{\partial Q}{\partial t}\right)-j\left(\frac{\partial P}{\partial t}\right)+k\left(\frac{\partial Q}{\partial x}-\frac{\partial P}{\partial y}\right)
$$

gdzie: $F$ - wektor przemieszczenia, $P, Q$ - składowe wektora przemieszczenia, $i, j, k$-wektory jednostkowe. Wskazuje ona że sąsiednie punkty, względem obliczanego, poruszają się ruchem zgodnym ze wskazówkami zegara (rys. 4a) lub przeciwnie (rys. 4b). Rotacja w tym punkcie, jest odpowiednio dodatnia lub ujemna. Jeżeli nie zachodzi ruch okrężny, wartość rotacji jest zerowa.

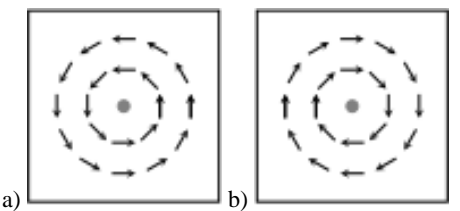

Rys. 4. Rodzaje badanych typów rotacji a) lewoskrętnej oraz b) prawoskrętnej

\section{Wyniki}

Obszar rejestracji kamerą, w zakresie światła widzialnego, obejmuje powierzchnię większą niż obserwowane zjawisko. Zarejestrowana ramka poza ruchem paliwa zawiera fragmenty zbędnych informacji. Należy do nich fragment palnika, przestrzeń, w której nie zachodzi ruch pyłu węglowego czy odbicie pyłu przed przejściem do rury opadowej.

Każdy krok, opisanej analizy ruchu, powoduje nieznaczne skrócenie sekwencji oraz zmniejszenie wielkości każdej ramki. Założenie wykonania badania dla całej sekwencji wejściowej nie jest możliwe. Jednak wielkość każdej ramki oraz długość sekwencji nie wpływa negatywnie na wskazanie właściwego obszaru zjawiska.

Do przedstawienia wyników, kolejnych kroków analizy ruchu paliwa, wybrano fragment ramki oraz fragment sekwencji. Wybrany fragment ramki ma wielkość $100 \times 140$ px co w przeliczeniu na rzeczywiste wymiary daje obszar $14 \times 20 \mathrm{~mm}$. Z całej sekwencji wybrano dwie, występujące po sobie, ramki (rys. 5), które reprezentują w pełni zaobserwowane zjawisko. Pomiędzy tymi ramkami można zaobserwować wyraźnie ruch i dokonać oceny empirycznej otrzymanych wyników.
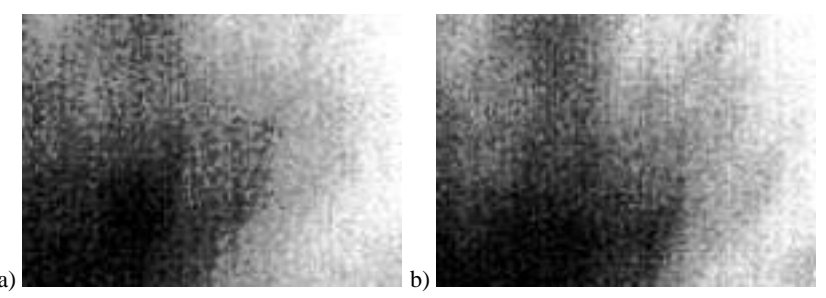

Rys. 5. Dwie: a) 200 oraz b) 201 wybrane do badania ramki sekwencji o wymiarach $100 \times 140 \mathrm{px}$

Zaproponowana filtracja ramki miała zwiększyć dokładność wyznaczenia pola wektorowego. $\mathrm{W}$ przeprowadzonym badaniu ruch paliwa przechodzi płynnie pomiędzy kolejnymi ramkami oraz pomiędzy sąsiednimi obszarami. Widocznym efektem filtracji ramki było zwiększenie kontrastu zjawiska oraz poprawna 
czytelności przebiegu zjawiska. Jednak po wyznaczenie pola wektorowego, dla odfiltrowanej sekwencji, wynik wskazuje na brak płynności ruchu cząstek pyłu węglowego.

$\mathrm{Na}$ przedstawionym, przykładowym polu wektorowym (rys. 6), można zaobserwować wektory wskazujące na przesunięcie w kierunku punktów sąsiednich. W kilku przypadkach, wskazany punkt sąsiedni, który powinien być kontynuacją ruchu, wskazuje na prędkość zerową lub wręcz, jego zwrot jest skierowany $\mathrm{o} 90^{\circ} \mathrm{w}$ kierunku odmiennym. Patrząc globalnie na ten problem, wektory z prawej części rysunku (rys. 6) wskazują na ruch obiektów w lewą stronę. W połowie szerokości następuje nagła zmiana ruchu. Za to, wektory z lewej części rysunku, zmieniają nagle kierunek, wskazując na ruch obiektów w dół. Pomiędzy tymi grupami wektorów brakuje płynnego przejścia. Nie jest to zgodne $\mathrm{z}$ rzeczywistym postrzeganiem ruchu badanego paliwa Po wyłączeniu filtracji, otrzymane pole wektorowe, dla tych samych ramek sekwencji, jest bliższe postrzeganemu ruchowi rzeczywistemu.

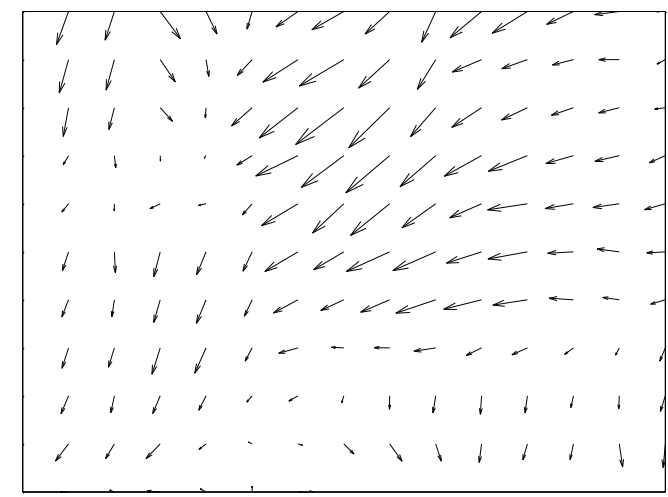

Rys. 6. Pole wektorowe ramki 200 i 201 wyznaczone po filtracji

Dobranie prawidłowej wielkości okna, podobnie jak filtracja polegało na obserwacji płynności otrzymanego pola wektorowego. Zbyt małe okno metody Lucas-Kanade, poniżej $20 \times 20$ px, uniemożliwiło identyfikację ruchu jakiejkolwiek grupy punktów (rys. 7). Z takiego pola wektorowego wynika, że każdy punkt porusza się $\mathrm{w}$ kierunku oraz $\mathrm{z}$ prędkością niezależna od punktu sąsiedniego. Okno zbyt duże, powyżej 40x40px, powoduje, że w grupach punktów można dostrzec płynną zmianę kierunku wektorów przesunięcia, jednak trudno jest dostrzec różnicę prędkości tych grup. Nie jest to odzwierciedleniem ruchu rzeczywistego. Prędkość oraz rozdzielczość badanej sekwencji obserwowanego zjawiska pozwoliła wyznaczyć przedział okna metody LucasKanade, między $20 \times 20$ px, a $40 \times 40$ px. Dalsze wyniki oparte są o pole wektorowe jest obliczane dla wielkości okna 40×40 px (rys. 8).

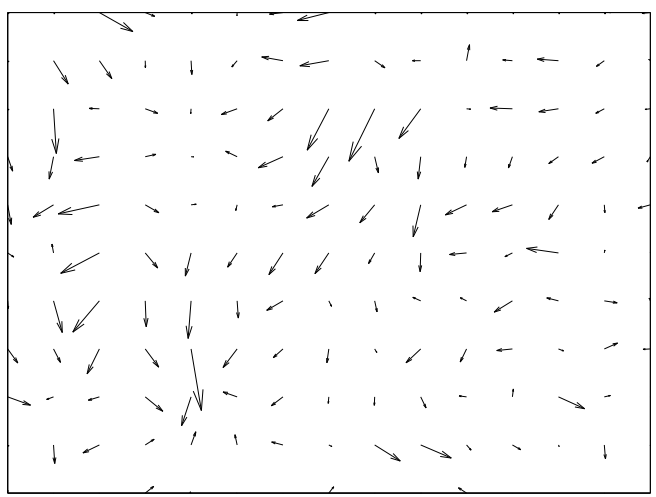

Rys. 7. Pole wektorowe ramki 200 i 201 dla okna $10 x 10$ metody Lucas-Kanade
Pochodne cząstkowe obliczone metodą różnic skończonych $(2-4)$, tworzą kolejne sekwencje danych. Dla każdej składowej wektora, względem jednej ze zmiennych, otrzymujemy sześć sekwencji pochodnych cząstkowych, równych wielkości ramki i długości sekwencji wejściowej. Z tak przygotowanych pochodnych można wykonać podsumowanie wyników, określających rodzaj ruchu.

Jedno z dwóch równań, opisane na pochodnych cząstkowych, określa ruch $\mathrm{w}$ formie dywergencji. Dla każdego punktu ramki obliczana jest dywergencja (5). Dla całej sekwencji powstaje sekwencja powierzchni dywergencji. Kontynuując analizę fragmentu ramek 200 i 201 otrzymujemy wizualizację dywergencji (rys. 9). Jedna powierzchnia mapy kolorów obrazuje trzy rodzaje przemieszczenia dywergencji. Jasny kolor mapy wskazuje na napływ paliwa do punktu. Ciemny kolor oznaczone miejsca z których paliwa odpływa. Miejsca przepływu, dywergencja zerowa, nie zostały zaobserwowane. Dla takiego rodzaju ruchu należy założyć pewien zakres wartości bliskich zeru.

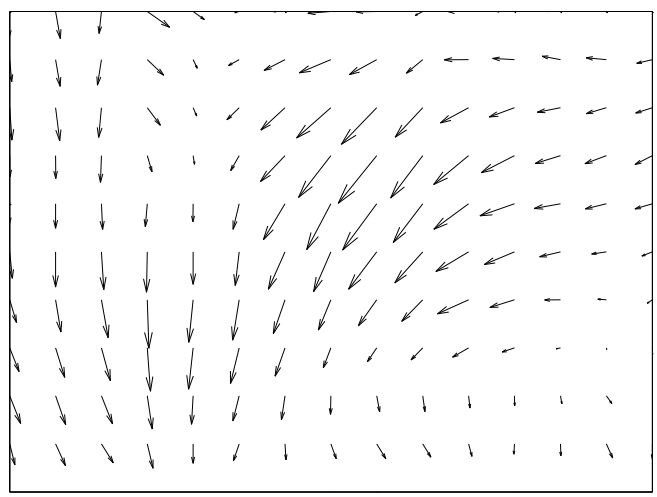

Rys. 8. Pole wektorowe ramki 200 i 201 dla okna $40 \times 40$ metody Lucas-Kanade

Drugim równaniem, opisującym rodzaj ruchu oraz składającym się z pochodnych cząstkowych jest rotacja. Rotacja liczona jest, dla każdego punktu ramki, równaniem (6). Dla całej sekwencji obrazu wejściowego, powstaje sekwencja powierzchni rotacji. Podtrzymując badanie fragmentu ramki i sekwencji otrzymujemy wizualizację rotacji (rys. 10). Powierzchnia ta, poprzez odcień koloru, obrazuje trzy rodzaje ruchu rotacyjnego. Jasny odcień zielonego, rotacja dodatnia, wskazuje na ruch przeciwny do ruchu wskazówek zegara. Ciemny odcień, rotacja ujemna, wskazuje na ruch zgodny z ruchem wskazówek zegara. Wartość zerowa, wskazująca na brak dowolnej rotacji, nie wystąpiła w przeprowadzonych obliczeniach. Można empirycznie wskazać, tak samo jak dla dywergencji, pewien zakres wartości bliskich zeru świadczących o braku rotacji.

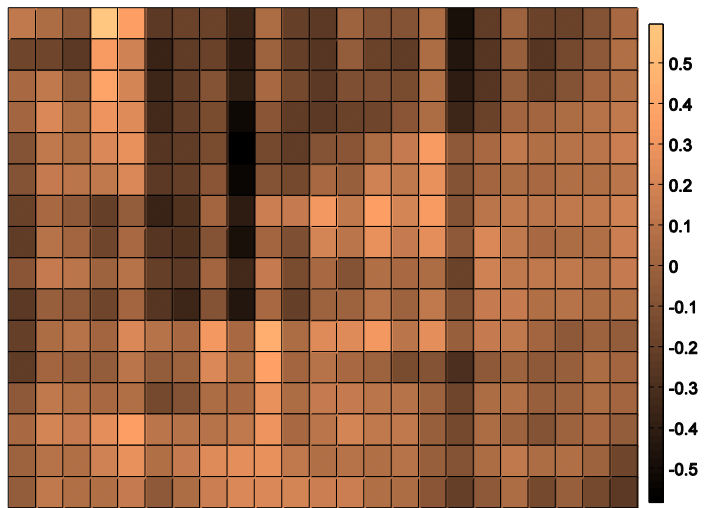

Rys. 9. Wizualizacja dywergencji badanego pola wektorowego 


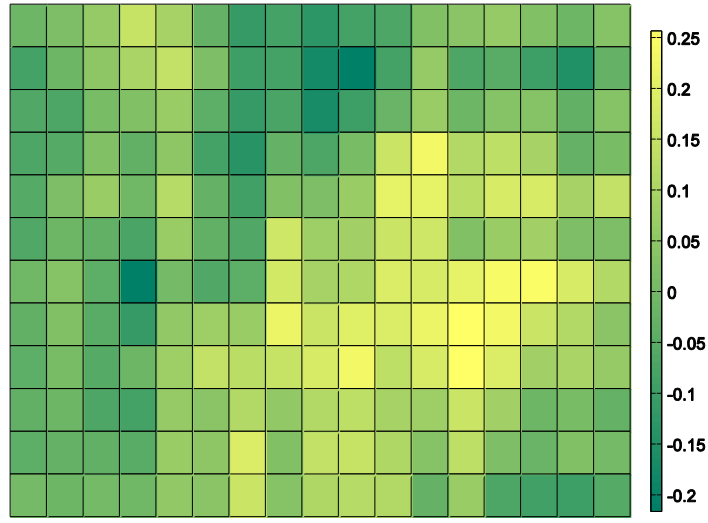

Rys. 10. Wizualizacja rotacji badanego pola wektorowego

\section{Wnioski}

Filtracja, w postaci różnicy ramek oraz wyrównania histogramu, badanej sekwencji wejściowej, pomimo poprawy kontrastu i wyeksponowania detali zarejestrowanego zjawiska, wpływa negatywnie na wyznaczenie pól wektorowych. Obserwując obliczone pole wektorowe, występuje brak ciągłości zarówno kierun$\mathrm{ku}$ jak i długości wektorów sąsiednich. Jest to sprzeczne z rzeczywistym ruchem paliwa.

Metoda Lucas-Kanade bardzo dobrze sprawdziła się przy wyznaczaniu pola wektorowego. Do badanego zjawiska, prędkości oraz wielkości przemieszczających się cząstek pyłu węglowego, wymagane było dobranie odpowiedniej wielkości okna.

Nie jest możliwe, z rzeczywistej sekwencji, otrzymanie dywergencji lub rotacji zerowej. Aby wskazać miejsca przepływu dywergencji lub braku rotacji na obrazie, należy wyznaczyć przedział wartości bliskich zeru.

Jeżeli dla metody różnic skończonych zostanie wybrana pojedyncza wartość punktu sąsiedniego, dywergencja lub rotacja przyjmuje wartości znacznie odstające od punktów sąsiednich. Wyznaczanie pochodnych cząstkowych wymagało obliczenia wartości średniej $\mathrm{z}$ punktów sąsiednich, co wygładziło szum i zwiększyło płynność ruchu cząstek pyłu węglowego.

$\mathrm{Na}$ tym etapie badań, trudne jest określenie szczegółowych parametrów doboru paliwa czy mieszanki paliwowo-gazowej. Do opisania zależności między zaobserwowanym ruchu, a kontrolą dostarczania paliwa, badanie wymaga dokładnego opisu czynności dostarczenia paliwa, powiązanego z czasem rejestrowanej sekwencji. Prezentowane badania mają na celu wskazanie narzędzi oraz sposobu pomiaru ruchu pyłu węglowego. Otwiera ono możliwości dokładnych badań określających wpływ ruchu paliwa na parametry procesu spalania.

\section{Podziękowania}

Badania były finansowane z grantu: 2012/07/B/ST7/01216 Narodowego Centrum Nauki.

Autor kieruje podziękowania dla zespołu naukowego prof. Haliny Pawlak-Kruczek za wykonanie eksperymentu oraz dla dr inż. Wojciecha Rafajłowicza za rejestrację oraz udostępnienie zebranych materiałów.

\section{Literatura}

[1] Altawell N.: Co-Firing Issues. Wiley-IEEE Press, 2014

[2] Barron J.L., Fleet D.J., Beauchemin S.S., Burkitt T.A.: Performance of optical flow techniques. Proceedings 1992 IEEE Computer Society Conference on Computer Vision and Pattern Recognition, Champaign, IL, 1992, 236-242 [DOI: 10.1109/CVPR.1992.223269].

[3] Branning R.L., Peizer M.J.: Profiting from pulverising. Power Engineer 21(1)/2007, 28-33.

[4] Bruce D.L., Takeo K.: An iterative image registration technique with an application to stereo vision. Proceedings of the 7th international joint conference on Artificial intelligence -IJCAI'81, Vol. 2. Morgan Kaufmann Publishers Inc., San Francisco, CA, USA, 1981, 674-679.

[5] Carter R.M., Yan Y.: Digital imaging based on-line particle sizing of 'green' biomass fuels in power generation. 2007 IEEE Instrumentation \& Measurement Technology Conference IMTC 2007, Warsaw, 2007, 1-4 [DOI: 10.1109/IMTC.2007.379414].

[6] Coal Facts 2014. IEA Coal Information 2014, BP Statistical Review of World Energy 2014, September 2014.

[7] Duo Sun, Gang Lu, Hao Zhou, Yong Yan, Shi Liu: Quantitative assessment of flame stability through image processing and spectral analysis. IEEE Transactions on Instrumentation and Measurement 64(12)/2015, 3323-3333.

[8] Hobson D.M., Carter R.M., Yong Yan, Zhixin Lv.: Differentiation between coal and stone through image analysis of texture features. IEEE International Workshop on Imaging Systems and Techniques, IST2007, Krakow 2007.

[9] Li Xiao-yu, Yang Xiao-xi, Gong Bo, Feng Hong-qing, Cheng Gang, Liu Xiaojie. Optimal ratio of oil-sludge and coal mixed fuel. International Conference on Materials for Renewable Energy \& Environment, Shanghai, 2011, 1650-1653 [DOI: 10.1109/ICMREE.2011.5930650].

[10] Mitchell A.R., Griffiths D.F.: The finite difference method in partial differential equations. Wiley, Chichester [Eng.], New York 1980.

[11] Patel V., Saha B., Chatterjee K.: Fuel saving in coal-fired power plant with augmentation of solar energy. International Conference on Power, Control and Embedded Systems (ICPCES), 2014, 1-5.

[12] World Coal Institute. The coal resource: A comprehensive overview of coal. UK London, September 2005.

\section{Mgr inż. Lukasz Pater \\ e-mail: lukasz.pater@pwr.edu.pl}

Wykształcenie wyższe techniczne zdobył na Wydziale Elektroniki Politechniki Wrocławskiej w specjalności Zastosowanie Inżynierii Komputerowej w Technice. Dyplom magistra uzyskał w 2011 roku. Zainteresowania naukowe to analiza i przetwarzanie obrazów. Obecnie doktorant w Zakładzie Systemów Wizyjnych i Teorii Sterowania

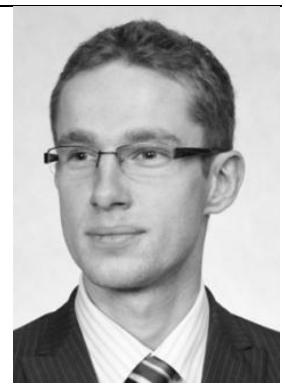

otrzymano/received: 15.06 .2016 przyjęto do druku/accepted: 11.05 .2018 